Article

\title{
Economic Transition and the Evolution of City-Size Distribution of China's Urban System
}

\author{
Jiejing Wang ${ }^{1} \mathbb{D}$ and Yanguang Chen ${ }^{2, *} \mathbb{( D}$ \\ 1 Department of Urban Planning and Management, School of Public Administration and Policy, \\ Renmin University of China, Beijing 100872, China; wangjiejing@ruc.edu.cn \\ 2 Department of Geography, College of Urban and Environmental Sciences, Peking University, \\ Beijing 100871, China \\ * Correspondence: chenyg@pku.edu.cn; Tel.: +86-106-276-6277
}

Citation: Wang, J.; Chen, Y. Economic Transition and the Evolution of City-Size Distribution of China's Urban System. Sustainability 2021, 13, 3287. https://doi.org/ $10.3390 /$ su13063287

Academic Editor: Alireza Ermagun

Received: 28 December 2020

Accepted: 8 March 2021

Published: 16 March 2021

Publisher's Note: MDPI stays neutral with regard to jurisdictional claims in published maps and institutional affiliations.

Copyright: (c) 2021 by the authors. Licensee MDPI, Basel, Switzerland. This article is an open access article distributed under the terms and conditions of the Creative Commons Attribution (CC BY) license (https:// creativecommons.org/licenses/by/ $4.0 /)$.

\begin{abstract}
The evolution of city size distribution in China has gained a great deal of scholarly attention. However, little is known about the effect of economic transition on the reorganization of city size distribution in China. Using an urban hierarchy with cascade structure model, we decompose Zipf's law into two exponential functions that provide a new way of examining the dynamic processes of urban system evolution. This study aims to investigate the dominating latent forces that affect China's city size distribution through mathematical modeling of the hierarchical scaling laws based on census data of 1982,1990, 2000, and 2010. A number of features of China's city size distribution are found. First, the size distribution of Chinese cities displayed a clear trend of evolving toward the Zipf distribution, which is the result of economic transition from planned to market. Second, the rank-size pattern still deviates slightly from the standard Zipf distribution, as indicated by the narrow scaling range and departure of the scaling exponent from the theoretically expected value. We argue that the top-down state regulation is a critical cause of deviation of China's city size distribution from Zipf's law.
\end{abstract}

Keywords: urban system; cascade structure; city size distribution; Zipf's law; Chinese cities

\section{Introduction}

The view that cities are self-organized systems is increasingly gaining general acceptance in Western intellectual contexts [1-4]. This view implies that city size distribution would follow Zipf's law if cities evolve toward being self-organizing or if they grow organically [5]. City evolution in Western countries is attributed primarily to bottom-up market forces consistent with self-organization rules. Driven by spontaneous forces, population and economic activities are distributed and shifted over space in a manner that generates an orderly city size distribution pattern. Many empirical findings have demonstrated that the balanced city-size distribution in a market economy could be described by a Zipf distribution [6-8]. By contrast, China seems to be a challenge when identifying this regularity that is mainly derived from the Western experience. The evolution of China's urban system has been considered to exhibit some distinct characteristics [9-16]. However, few studies have asked the "so what" question: what are the underlying causes of these distinctions in China's urban system? In explaining these distinctions, we must examine the latent socioeconomic factors that shape the evolution of China's urban system.

To achieve this goal, we employ a theoretical framework that centers on decomposing Zipf's law into a pair of exponential functions that represent two opposing processes from which city size distribution is derived. Population distribution in cities reflects the balance of two opposing processes of centralization and decentralization. These two dynamic processes cannot be studied exclusively by Zipf's law. However, using the urban hierarchy scaling law, this paper decomposes Zipf's law into two exponential functions that provide 
a new way of examining the two opposing dynamic processes of urban system evolution and the underlying driving forces.

The state and the market are two major forces of urban development in China [17]. The development of Chinese cities between 1949 and 1978 was attributed primarily to causal factors controlled by the state, after the country broke its foreign ties and ceased the existence of market mechanisms, and integrated all economic activities into a centrally planned economy [18]. The socialist ideology with derivative urban policies and development programs was the major force of urban system development during the period $[19,20]$. The socialist state with its market-oriented reforms has undergone fundamental and profound transformation since 1978 [21]. Two critical reforms have led to this transformation: the implementation of the reform and opening-up policies in 1978 and the establishment of the socialist market economy in 1992. However, China has maintained a stronger role of the state than that of Western countries, influencing urban system development through institutional factors and policies [22,23]. As pointed out by many scholars, China's transition is not in convergence with that of Western neoliberal countries because the role of the state in economic development and social governance remains crucial [24,25]. Although constraints have become more flexible, regulations, such as the Hukou system (The transliterated word Hukou in this study means the household registration system, representing a Chinese characteristic) and the urban administrative system, continue to have important effects on urban development [26]. Therefore, the growth of Chinese cities in the post-reform era should be attributed to both the state's top-down force and the market's bottom-up force. The present study aims at exploring the characteristics of China's city size distributions and the deeper causes of urban system development in the post-reform era. We aim to answer the following questions: to what extent do the market-oriented reforms and the state of China, which maintain a vital role in the economic transition, affect the city size distribution in China?

The theoretical background of this study is highlighted below. Zipf's law is one of the signs of self-organized criticality [27]. If an urban system evolves into a self-organized critical state, the rank-size distribution will most likely follow Zipf's law and exhibit fractal properties [12]. As Cristelli et al. emphasized, Zipf's law could be considered as the "ultimate signature" of an integrated system with a "coherence" sample, which is the outcome of a self-organization mechanism of a system with regard to finite resources [28]. The rank-size pattern indicates a scaling relation and dynamic balance between equity for parts and efficiency for the entire unit [29]. The remainder of this paper is organized as follows. Section 2 presents the theoretical framework for the empirical analysis. Section 3 shows the results of the empirical analysis. Section 4 discusses the effects of economic transition on China's urban system development. Section 5 concludes the study.

\section{Methods and Data}

\subsection{Theoretical Model}

According to Zipf's law, city size distribution in a region that is sufficiently large follows the power law [30]. Mathematically, if the product of the population of a city $P_{k}$ and its rank $k$ to the power of $q$ equals the population of the largest city $P_{1}$, we can state that the city size distribution follows Zipf's law. The general form of Zipf's law is:

$$
P_{k}=P_{1} k^{-q}
$$

where $q$ refers to the Zipf exponent. If $q=1$, then Equation (1) will become the pure form of Zipf's law, which is also known in urban geography as the rank-size rule. Equivalently, Pareto's distribution is expressed as:

$$
N(r)=C r^{-\alpha}
$$

where $r$ denotes a critical size scale, $N(r)$ refers to the cumulative number of cities greater than or equal to $r, C$ denotes the proportionality constant, and $\alpha$ is the Pareto scaling 
exponent. Zipf's law and the Pareto distribution in city size distribution are two sides of the same coin [31].

In mathematics, Zipf's law can be decomposed into a pair of exponential functions through urban hierarchy with a cascade structure model. If we define $P_{1}=1$ unit, then the standard rank-size distribution can be abstracted as a geometric sequence $\left\{1 / k^{q}\right\}$, where $k=1,2,3, \ldots$. By the $2^{n}$ rule, this geometric sequence can be divided into $M$ top-down order classes, with 1 city at the first level, 2 cities at the second level, 4 cities at the third level, and $2^{m-1}$ cities at the $m$ level $(m=1,2, \ldots, M$, and $M$ can be theoretically infinite) (Figure 1). Thus, we obtain the following exponential functions that represent the generalized $2^{n}$ rule of the cities [32]:

$$
\begin{aligned}
& f_{m}=f_{1} r_{f}^{m-1} \\
& P_{m}=P_{1} r_{p}^{1-m}
\end{aligned}
$$

where $f_{m}$ and $P_{m}$ denote the city number and the average city size in the $m$ th class, $r_{f}=f_{m+1} / f_{m}$ and $r_{p}=P_{m} / P_{m+1}$ are the number ratio and size ratio, and $f_{1}$ and $P_{1}$ are the city number and city size of top-level cities, respectively. The two exponential functions comprise the cascade structure model of the urban hierarchy. From Equation (3) and Equation (4), the hierarchical scaling law of cities follows the form:

$$
f_{m}=\mu P_{m} r_{p}^{-D}
$$

where $\mu=f_{1} P_{1}{ }^{D}$ denotes constant proportionality and $D=\ln r_{f} / \ln r_{p}$ refers to the fractal dimension of urban hierarchy and city size distribution. The previously mentioned mathematical processes described the mathematical derivations of the two exponential functions from Zipf's law $[29,33,34]$ (The strict mathematical proof and derivation, including the mathematical relationships between Zipf's law and hierarchical scaling law, the derivation of hierarchical scaling law by entropy-maximizing methods, and the intervals of related parameters, have been performed by Chen). Theoretically, the fractal dimension $D$ is equivalent to the Pareto scaling exponent $\alpha$ and to the reciprocal of the Zipf exponent $q$. Jiang and Yao have shown that the better the city size distribution satisfies the rank-size rule, the more consistent the estimated values of these parameters $(D, \alpha, q)$ [35]. Hence, the following relationship exists among them [34] (In empirical studies, the estimated values of parameters $D, \alpha$, and $q$ may differ, but may be insignificant if the city size distribution follows Zipf's law):

$$
D=\frac{\ln r_{f}}{\ln r_{p}}=\alpha=\frac{1}{q}
$$

Furthermore, utilizing the hierarchical correlation models and the ideas from multifractals, Chen demonstrated that the interval of $D, \alpha$, and $q$ is $(0.5,2)$, and their expected values approach 1 [33], that is:

$$
\frac{1}{2}<D, \alpha, q<2, D=\alpha=\frac{1}{q} \rightarrow 1
$$

The expected scaling exponent is 1 if an urban system approaches its optimization state. If $D=\alpha>1$, and accordingly $q<1$, then large cities are theoretically smaller than expected (underdeveloped), whereas medium and small cities are larger than the predicted values (overdeveloped). By contrast, if $D=\alpha<1$, and accordingly $q>1$, then large cities are overdeveloped, whereas medium and small cities are underdeveloped. 


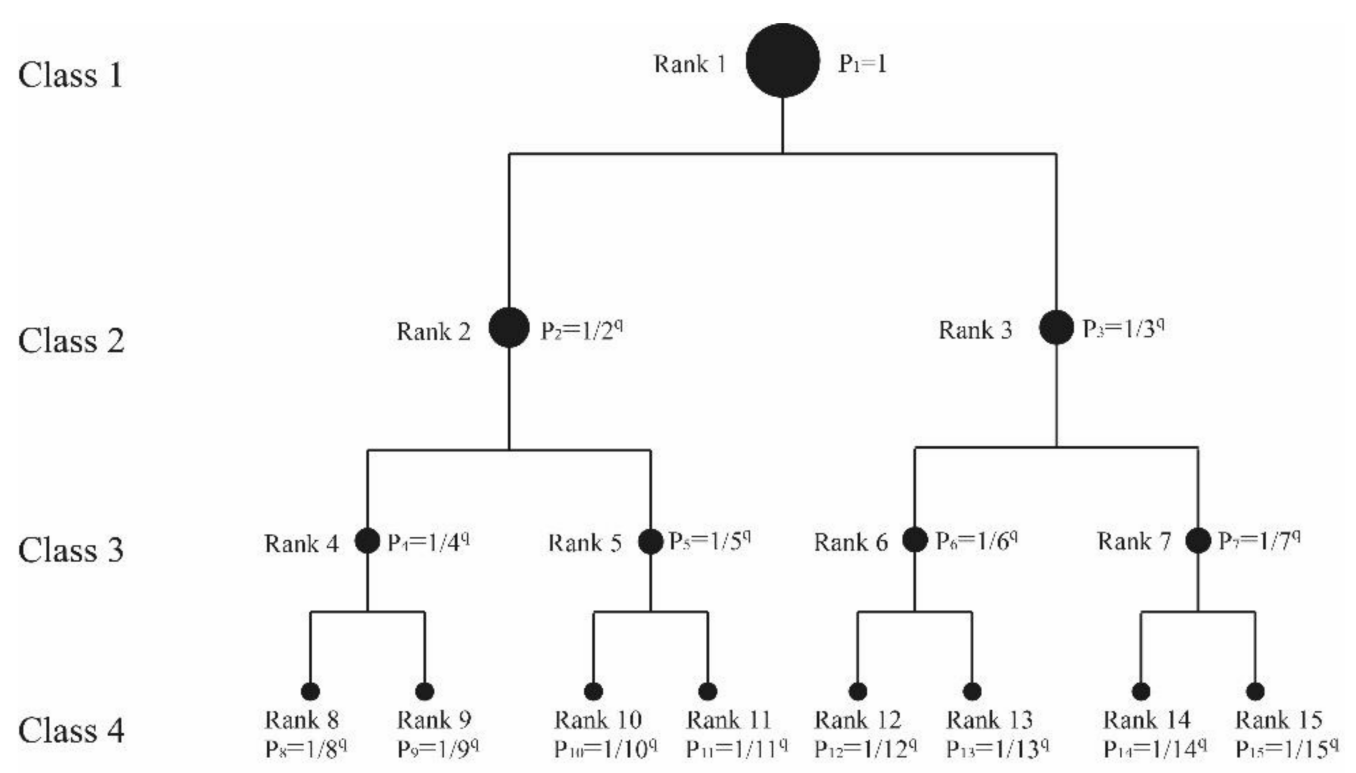

Figure 1. The schematic diagram of urban hierarchy with cascade structure model based on the generalized $2^{n}$ rule. Source: Chen [34].

In empirical studies, these two functions represent two opposing processes of the urban system evolution (Figure 2). Equation (3) reveals the Pareto effects (number law), that is, a process in which cities attempt to become increasingly numerous and pursue equity for parts or individuals. Thus, population distribution is more decentralized over cities. By contrast, Equation (4) reveals the Zipf effect (size law), which is a process in which each city attempts to become increasingly large and pursue efficiency of the entire urban system and results in the population distribution becoming rather centralized. The former process is associated with the top-down force of state intervention, whereas the latter is associated with the bottom-up effects of the market force [17]. Over time, an optimized a Zipf distribution can be achieved if the two opposing forces become more balanced. Using this theoretical framework, we can investigate the influences of both the state and the market on urban system evolution.

Our analytical approach includes three major steps. The first step is the quantification of city size distributions of China's urban system from 1982 to 2010 based on Zipf's law. The second step involves the analysis of the hierarchical structure and evolutionary features using the two exponential functions obtained above. The third step involves comparing the results of the first two steps. From these two steps, we can clearly figure out the evolutionary trajectories of China's urban system over the past three decades. More importantly, the influences of the state and the market on urban system evolution can be discussed by connecting the results of the analysis with policy and institutional changes during China's reform era.

\subsection{Data}

In this study, city size is based on the "city population" (shi renkou), and is drawn from the population census data. Many previous studies based city size on the "urban non-agricultural population" (shiqu feinongye renkou), as reported in statistical yearbooks. The reference to the "non-agricultural population" has significant problems despite its temporal continuity because the figure undercounts the real size of a city with a large inflow population and overcounts the real size of a city with a large outflow population. The main cause of these problems is the identification of the "urban non-agricultural population" as primarily based on the people's Hukou status. With the increasing number of rural-urban non-Hukou migrants since the early 1990s, the "urban non-agricultural population" can no longer reflect actual city size. The population census data are comparatively more reliable. In particular, the measurement of "city population" is almost close to the actual city size [36]. 
The "city population" includes the non-Hukou migrants who are actually residents of the city. Thus, this measurement is better to calculate actual city size than the "urban non-agricultural population". We draw our datasets mainly from the population census data in 1982, 1990, 2000, and 2010 (Given the fact that the "city population" of the 1990 population census was clearly incomparable with the other three years, the non-agricultural population of 1990 was used as an approximation).

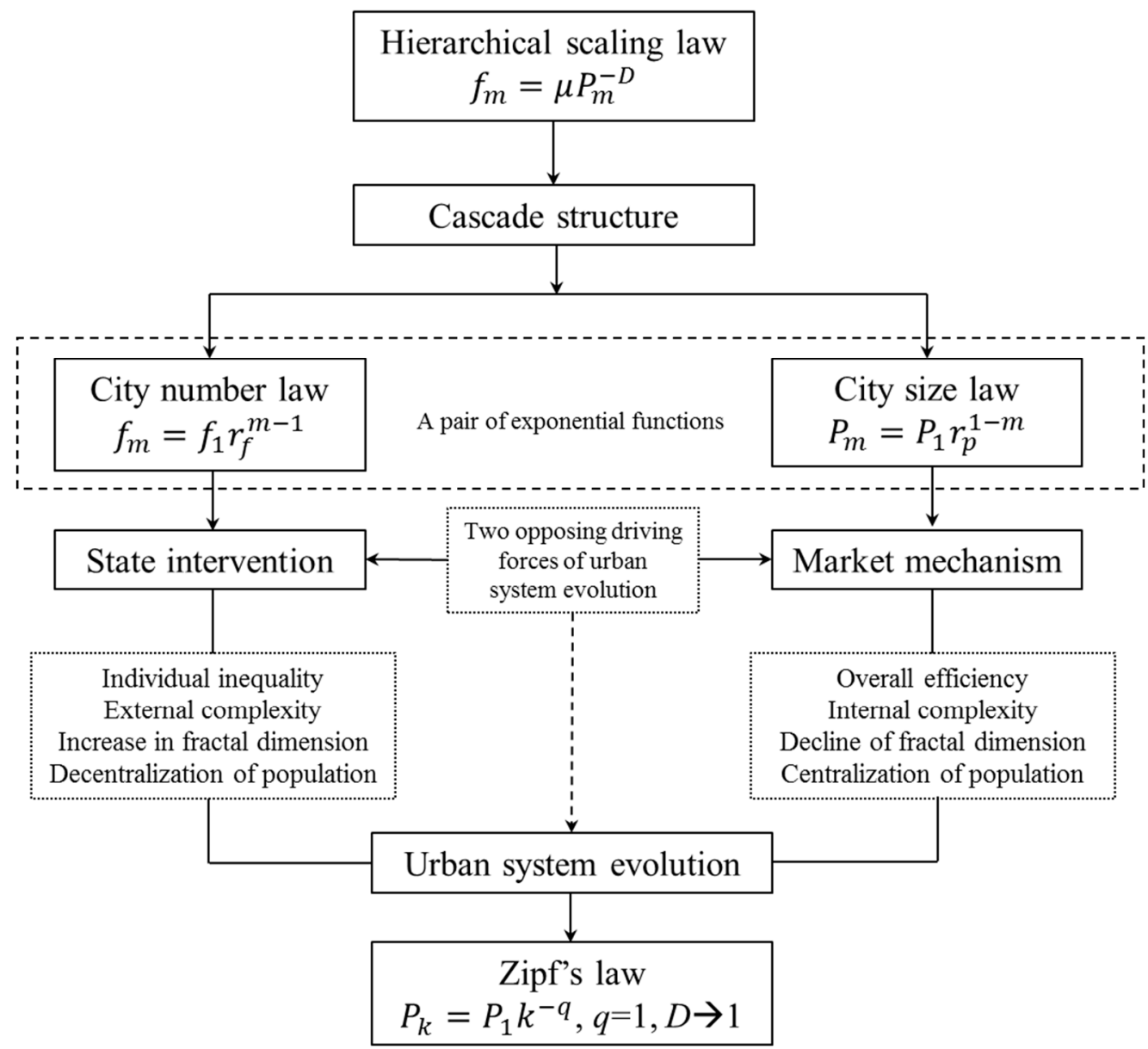

Figure 2. Basic logic of the hierarchical scaling law and urban system evolution. Note: The contents in this figure are summarized and supplemented according to Chen [34].

The current study uses the datasets including all officially designated cities in the corresponding years. All Chinese cities are categorized into four levels based on their political administrative status: provincial, deputy provincial, prefecture, and county levels. In determining the population of prefecture or high-level cities, we do not include the population of counties under their administrative jurisdiction because these counties only "belong" to them administratively. In the reports of four censuses, China had 238 cities in 1982, 460 cities in 1990, 666 cities in 2000, and 654 cities in 2010. Figure 3 shows the distribution of the top 100 Chinese cities in 1982 (Figure 3a) and 2010 (Figure 3b), based on which we can observe the evolution of the large cities during the three decades. 


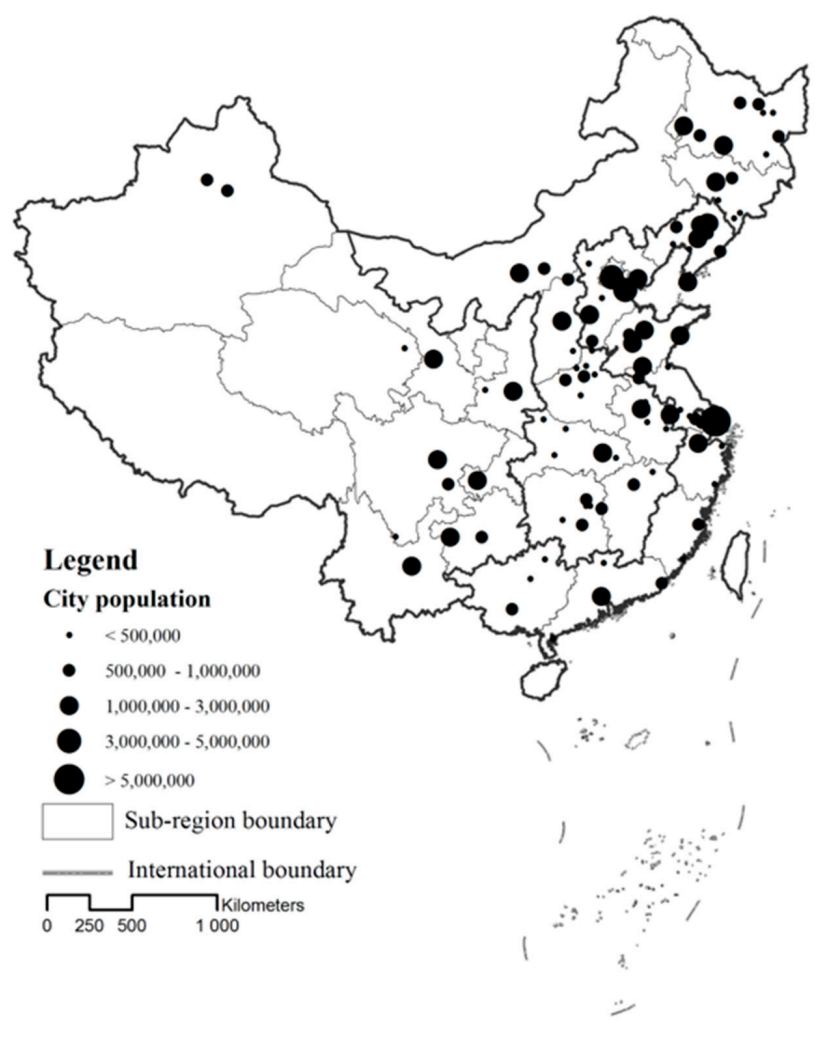

(a)

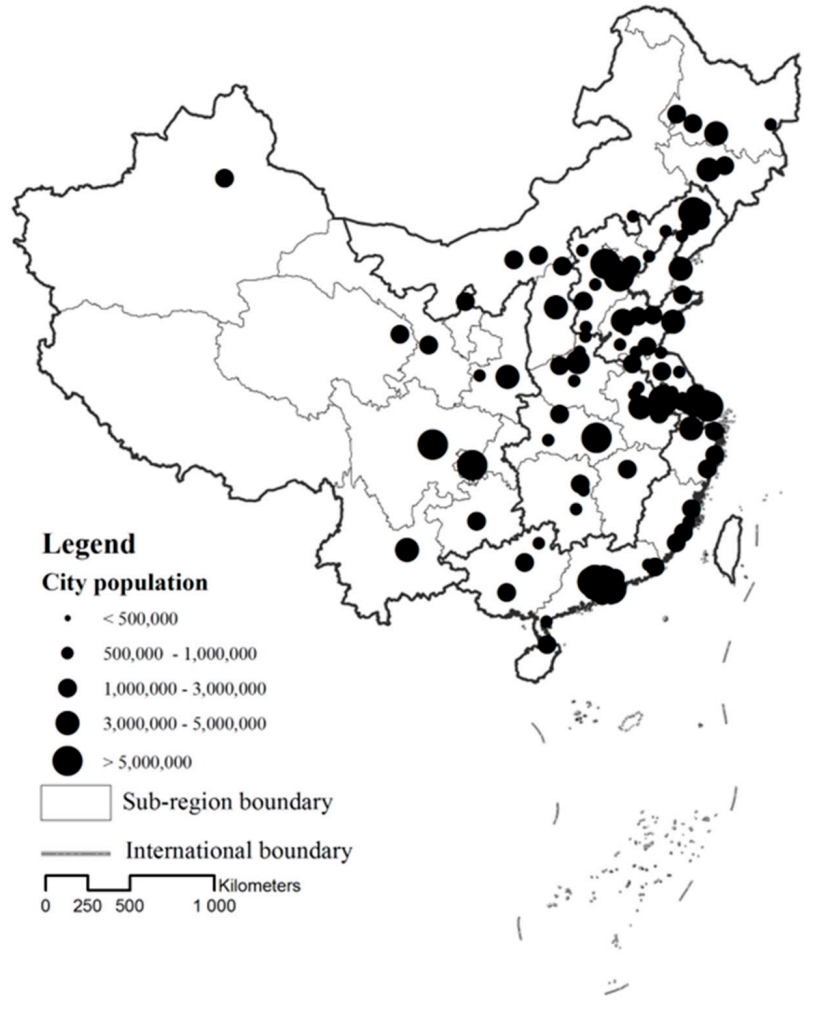

(b)

Figure 3. Distribution of top 100 Chinese cities in 1982 (a) and 2010 (b). Source: Chinese Statistical Bureau.

\section{Results}

Zipf's law can reflect several key macro-level features of the outcome of city size distribution, whereas the urban hierarchy with a cascade structure model can illustrate two major and at times contradictory processes of urban system evolution at the micro-level. First, we begin by analyzing the macro-outcome of the city size distribution of the urban system based on Zipf's law. The rank-size patterns are displayed in the log-log plots, and Zipf exponents are calculated by fitting the model to the data points in the scaling ranges (Figure 4). The city size distributions evidently bear the properties of the Zipf distribution, suggesting that China's urban system conforms to Zipf's law. The Zipf exponent gradually approaches 1, from 0.795 in 1982 to 0.925 in 2010. In 1982, the Zipf exponent is significantly smaller than the expected value of 1 , suggesting that the large cities were underdeveloped. Although the growth of large cities was relatively faster thereafter, as shown by the Zipf curve becoming steeper in the log-log plots, the top cities remained smaller than the theoretically expected size based on Zipf's law. By contrast, the droopy tail of the city size distribution phenomenon suggests that the cities at the lower level are markedly undersized. Thus, the scaling range is considerably narrow because many of the cities are too small to be included. For example, only 120 cities were included in the 1982 scaling range, and the goodness of fit was approximately 0.968 . In 1990, the scaling range widened because of the continuous upgrading of counties to cities. In 2000 and 2010, the scaling ranges covered most of the designated cities (approximately 550 cities). The goodness of fit values considerably approximate to 1 , indicating that the city size distribution in China was increasingly becoming consistent with the Zipf distribution. 

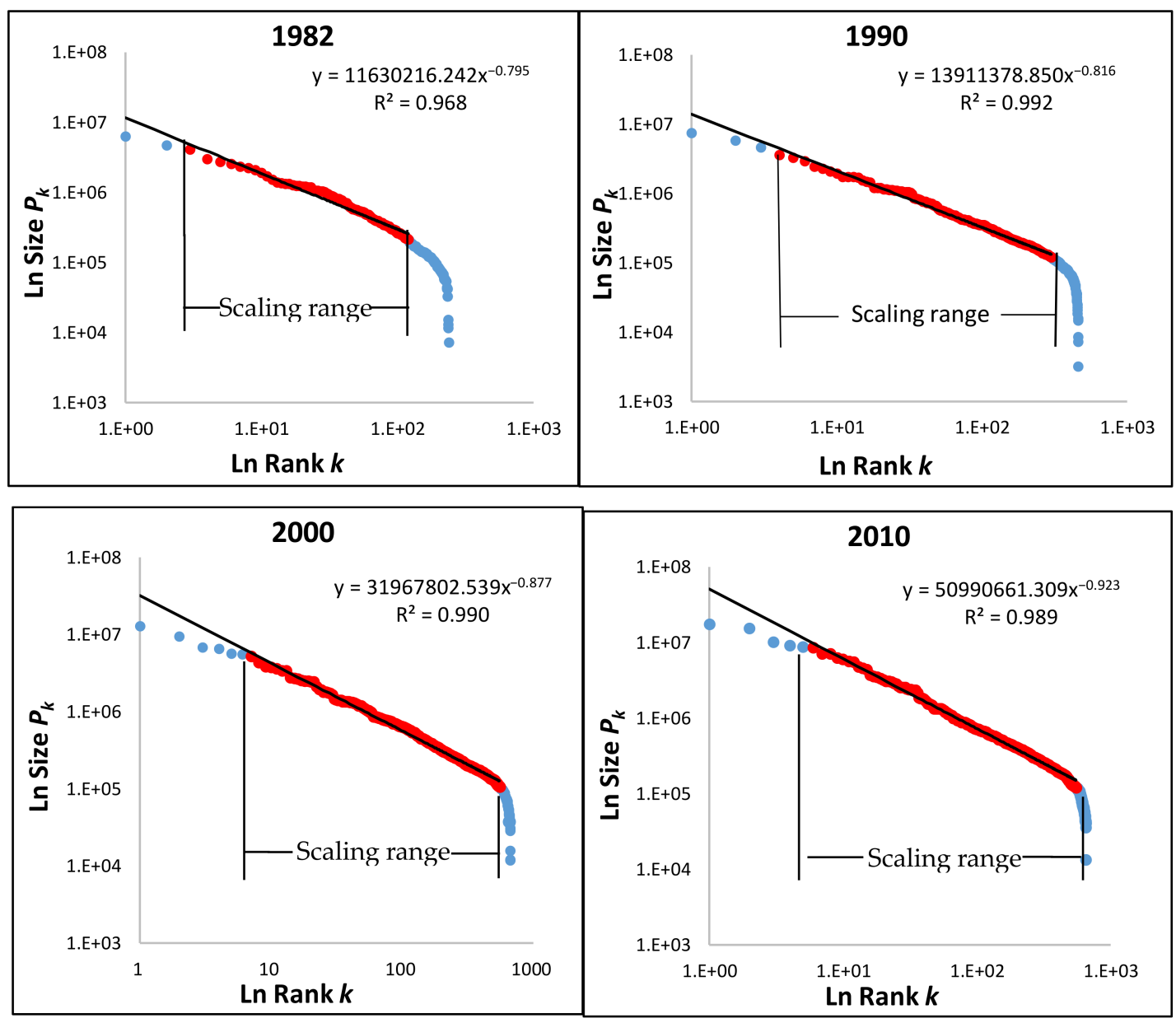

Figure 4. Rank-size patterns of China's urban system in 1982, 1990, 2000, and 2010. Source: Chinese Statistical Bureau; 2000 data were drawn from Zhou and Yu [36].

We now proceed to analyze the evolutionary processes of China's urban system during the selected four years based on the urban hierarchy with a cascade structure model. As previously mentioned, we organize all the cities into a hierarchical system with a cascade structure using the $2^{n}$ principle. The first class has the largest city, the second class has two cities (second and third largest), the third class has four cities (fourth to seventh largest), and so on. The technique used in the data processing is similar to that of the box-counting method for fractal dimension measurement. The objective of reconstructing the cities by hierarchical scaling is to determine an effective parameter and to show the evolutionary processes of the urban system. Seven classes included 127 cities in 1982. The other years were categorized through analogy. Eight classes included 255 cities in 1990 and nine classes included 511 cities in both 2000 and 2010. For each class, we calculated the average population size $P_{m}$ and the size ratios $r_{p}$. Table 1 lists the results. Fitting Equation (5) to the city numbers and city size through the least squares method yields the fractal dimension for each year (Figure 5). 
Table 1. Urban hierarchy with cascade structure model of China's urban system in 1982, 1990, 2000, and 2010.

\begin{tabular}{|c|c|c|c|c|c|c|c|c|c|}
\hline \multirow{2}{*}{$m$} & \multirow{2}{*}{$f_{m}$} & \multicolumn{2}{|c|}{1982} & \multicolumn{2}{|c|}{1990} & \multicolumn{2}{|c|}{2000} & \multicolumn{2}{|c|}{2010} \\
\hline & & $P_{m}$ & $r_{p}$ & $P_{m}$ & $r_{p}$ & $P_{m}$ & $r_{p}$ & $P_{m}$ & $r_{p}$ \\
\hline 1 & 1 & $6,320,829$ & & $7,469,509$ & & $12,720,701$ & & $17,640,842$ & \\
\hline 2 & 2 & $4,397,004$ & 1.438 & $5,172,148$ & 1.444 & $8,177,726$ & 1.556 & $12,950,396$ & 1.362 \\
\hline 3 & 4 & $2,653,298$ & 1.657 & $3,061,403$ & 1.689 & $5,778,874$ & 1.415 & $8,512,504$ & 1.521 \\
\hline 4 & 8 & $1,691,846$ & 1.568 & $1,893,017$ & 1.617 & $3,513,397$ & 1.645 & $5,617,198$ & 1.515 \\
\hline 5 & 16 & $1,127,355$ & 1.501 & $1,201,374$ & 1.576 & $2,061,115$ & 1.705 & $2,999,553$ & 1.873 \\
\hline 6 & 32 & 628,812 & 1.793 & 704,224 & 1.706 & $1,170,093$ & 1.761 & $1,578,081$ & 1.901 \\
\hline 7 & 64 & 293,458 & 2.143 & 367,607 & 1.916 & 667,668 & 1.753 & 786,780 & 2.006 \\
\hline 8 & 128 & & & 196,327 & 1.872 & 345,750 & 1.931 & 439,690 & 1.789 \\
\hline 9 & 256 & & & & & 177,006 & 1.953 & 219,370 & 2.004 \\
\hline Average & & & 1.683 & & 1.689 & & 1.715 & & 1.746 \\
\hline
\end{tabular}

Source: Chinese Statistical Bureau; 2000 data were drawn from Zhou and Yu [36].
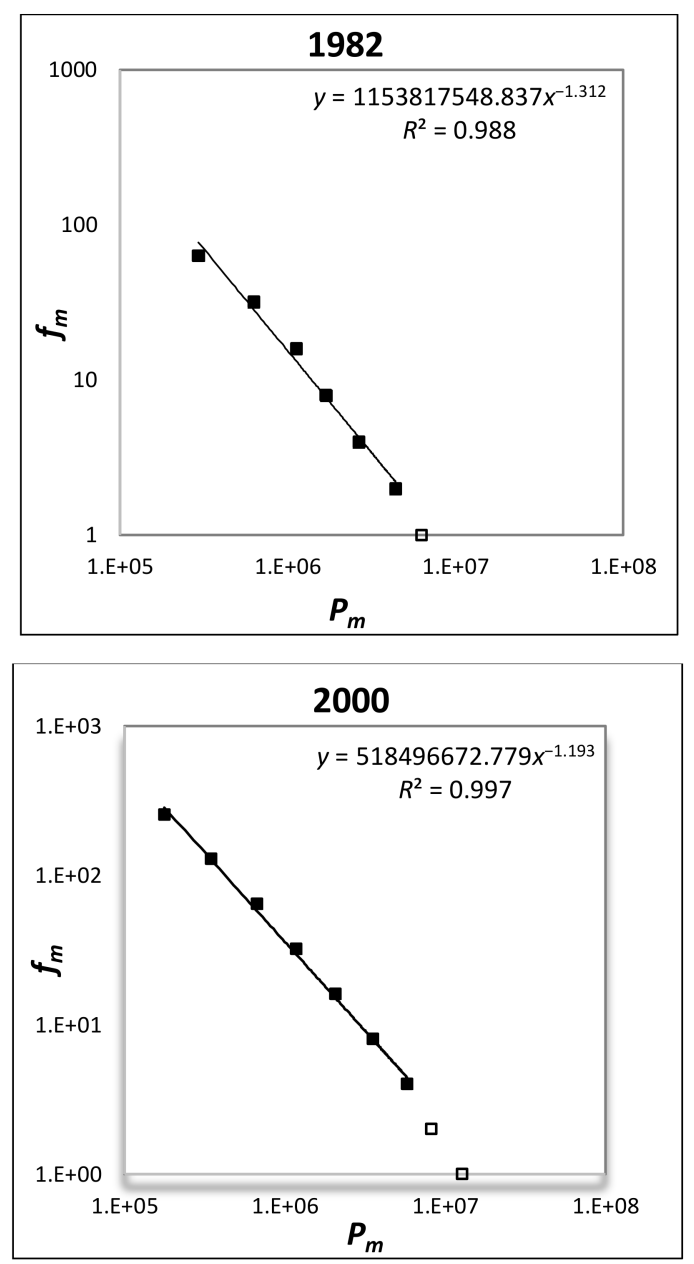
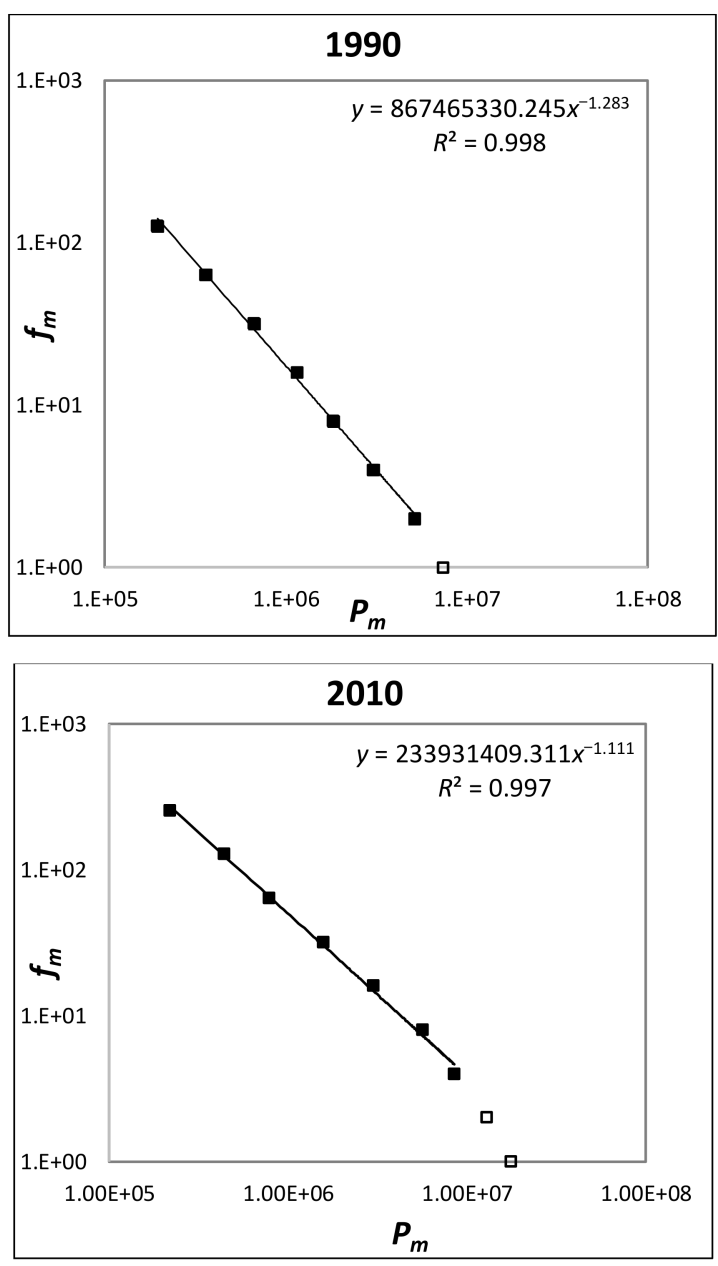

Figure 5. Patterns of hierarchical scaling laws of China's urban system in 1982, 1990, 2000, and 2010. Source: Chinese Statistical Bureau; 2000 data were drawn from Zhou and Yu [36].

The fractal dimension $(D)$ values gradually approach 1 from 1.312 in 1982 to 1.111 in 2010 (Table 2). The reciprocal of the fractal dimension $\left(q^{*}\right)$ became closer to the Zipf component $(q)$ during the study period. After synthesis of the empirical results, we can conclude that the city size distribution of China's urban system from 1982 to 2010 gradually evolved toward a more optimized system by self-organization. Particularly, by setting the city number ratio at the standard value of 2 , we can observe the continuous approach of the average city size ratio to 2, from 1.683 in 1982 to 1.746 in 2010 (see the last row of Table 1). 
These results imply the increase in overall efficiency and internal complexity of the system as well as recognition of the importance of the market as a driving force behind the urban system evolution. However, evidence (e.g., the fractal dimension is significantly higher than 1 , the difference between $q^{*}$ and $q$, and so on) also indicated that China's urban system may deviate slightly from the standard rank-size rule.

Table 2. Hierarchical scaling exponents of China's urban system in 1982, 1990, 2000, and 2010.

\begin{tabular}{cccccccc}
\hline \multirow{2}{*}{ Year } & \multicolumn{3}{c}{ Rank-Size Distribution } & \multicolumn{3}{c}{ Cascade Structure } \\
\cline { 2 - 8 } & $\boldsymbol{q}$ & $\boldsymbol{R}^{\mathbf{2}}$ & Scaling Range & $\boldsymbol{D}$ & $\boldsymbol{q}^{*}$ & $\boldsymbol{R}^{\mathbf{2}}$ & Scaling Range \\
\hline 1982 & 0.795 & 0.968 & Ranks 3 to 120 & 1.312 & 0.762 & 0.988 & Classes 2 to 7 \\
1990 & 0.816 & 0.992 & Ranks 4 to 300 & 1.283 & 0.779 & 0.998 & Classes 2 to 8 \\
2000 & 0.877 & 0.990 & Ranks 7 to 550 & 1.193 & 0.838 & 0.997 & Classes 3 to 9 \\
2010 & 0.923 & 0.989 & Ranks 6 to 550 & 1.111 & 0.900 & 0.997 & Classes 3 to 9 \\
\hline
\end{tabular}

Note: Corresponding with $D, q^{*}$ is computed by power function fitting after changing the dependent and independent variables.

\section{Economic Transition and Urban System Development in China}

In this section, we scrutinize the underlying causes of the evolution of China's urban system in the past three decades. In considering the causal factors of urban system evolution, the effects of economic transition are examined. Explanations of the effects of market mechanisms and state actions on city size distribution evolution are provided based on empirical evidence of the previous sections. Moreover, we also examine the extent to which state actions should be responsible for the deviation of China's city size distribution from the standard rank-size rule.

\subsection{Market-Oriented Reforms and Evolution of City Size Distribution}

Generally, our results indicate that China's city size distribution was evolving toward a standard Zipf distribution from 1982 to 2010 . The direct evidence is a continuous decrease in the fractal dimension from $D=1.312$ in 1982 to $D=1.111$ in 2010. As shown in Figure 6, the reform and opening-up policies implemented in the early 1980s and the establishment of the socialist market economy in 1992 may be considered as two landmarks that affected the evolution of China's urban system.

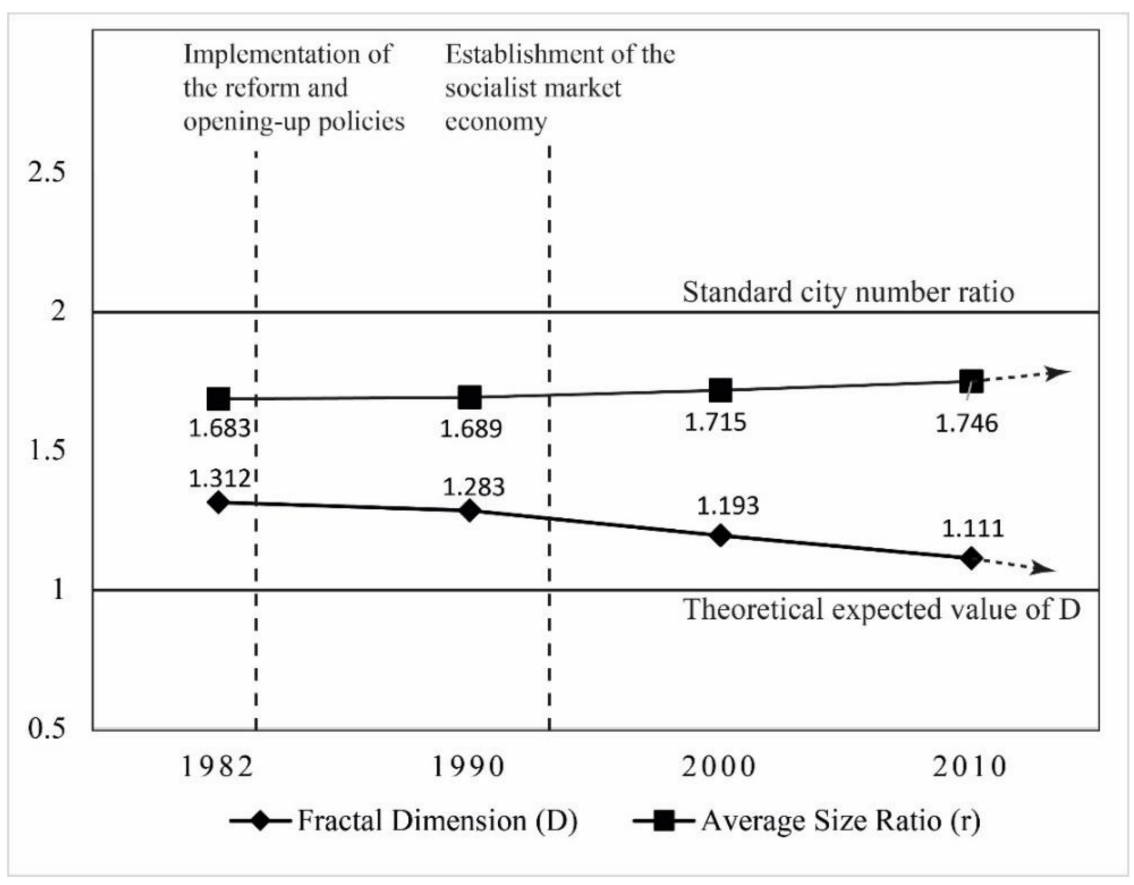

Figure 6. Evolution of the fractal dimensions and average size ratio from 1982 to 2010. 
As a country with a vast territory, large population, and a history of long-term urban development, China is most unlikely to form a primate city size distribution. However, these factors are not sufficient conditions to form a rank-size distribution of the entire country. Skinner explained that, for a long period, China's traditional urban systems evolved separately within several physiographic macro-regions based on major drainage basins [37]. Even at the end of the Qing Dynasty, a well-integrated national urban system had not emerged. By historicizing China's city size distributions in 1843, 1937, 1853, and 1970, Pannell further supported Skinner's viewpoints [18]. Chang argued that a more integrated national urban system has been gradually emerging since 1949, despite political fluctuations and overtones in development policies [20]. The results of our analysis indicate that the data points in the scaling range in the log-log plot in 1982 are not aligned in a straight line (Figure 4). Hence, no conspicuous scaling range and demarcation points appear to be present in the log-log plots. The goodness of fit is only 0.968 , indicating no potential standard log-linear relationship between the size of a city and its rank. All evidence suggests that Skinner's assertion that a nationally integrated urban system did not emerge at least until the early 1980s remains valid.

After the "new China" was established in 1949, all cities were integrated into one administrative system that adhered to the centrally planned economy. The construction of railroads, development of industrial bases, and redistribution of demographic characteristics intensified articulated linkages between physiographic regions. However, in the absence of market mechanisms, economic resources, preferred policies, and planning quotas were distributed downward through a rigid hierarchical administrative system instead of through market mechanisms. Such a top-down and centralized planning system strengthened vertical linkages between superior and subordinate administrative units, but weakened horizontal interactions among cities. This development mode was characterized by high growth rate, low efficiency, and compelled growth [38]. Conversely, key input factors, such as mobile labor, footloose capital, and tradable goods are primarily allocated by market mechanisms in a market economy. Thus, market potentials and geographic conditions are predominant in determining the variations of urban growth rates. In summary, the socialist economy, which internalized the market mechanisms into a centrally planned system, confined the bottom-up forces in the urban system evolution. The evolution of China's urban system during the socialist period was passively organized by external commands mainly from the central government, which deviated from the basic principles of self-organization. Hence, forming a standard rank-size distribution in such a political economy context was difficult.

In theory, the standard Zipf distribution reflects a balanced relationship between the equity for parts or individuals and the efficiency of the entire unit [29]. In this sense, market-oriented reforms increase the efficiency or internal complexity of the urban system by bringing in bottom-up market forces. The empirical evidence is the continuing growth of the average city size ratio $r_{\mathrm{p}}$ from 1.683 in 1982 to 1.746 in 2010 (Table 1). As the capital, labor, and land markets were established partially and gradually, cities were granted more autonomy to determine their own development strategies. Horizontal interactions among cities were also strengthened considerably because of the decentralization of administrative powers. Under the influence of an emerging market economy, the central government had to relax its tight controls on economic activities further, including easing restrictions on population movement, capital flow, and location choice of firms. The profound socio-economic changes during the post-reform period resulted in a new track of urbanization, which Shen termed the "spontaneous bottom-up track", and is different from the "state-sponsored top-down track" during the pre-reform era [39]. The opening-up policies also introduced the influences of globalization. Globalization led to "ex-urbanization" that characterizes the pattern of urban growth driven primarily by the inflow of foreign investments [40]. Market-oriented reforms and the opening-up policies have both contributed to the selforganization mechanism of the system of Chinese cities. A certain pattern of order has emerged at the macro-level of the urban system by revitalizing the micro-level interactions 
among cities. Therefore, China's city size distribution reflects a clear evolving trend from 1982 to 2010 toward the standard Zipf distribution.

\subsection{State's Influence on City Size Distribution}

Our results also suggest that China's city size distribution has not yet reached the point of equilibrium between equity for the parts or individuals and the efficiency of the entire urban system. One critical reason may be the state's control on urban development. The state and the market are two forces constantly involved in the operation of an economy. The relative strengths or weaknesses of the state and the market in a political economy determine their different capacities in allocating resources and directing economic activities. As previously stated, the relationship between the state and the market can be reflected by the variations of parameters of the two exponential functions. If the two forces are approximately balanced, then the average city size ratio $r_{p}$ should be extremely close to 2 because the city number ratio is postulated to be standard value $r_{f}=2$. Under such conditions, the fractal dimension $(D)$ and Zipf scaling exponent $(q)$ will simultaneously approach 1 . If the state is considerably stronger than the market, then such a condition will lead to $r_{f}>r_{p}$, and $D>1, q<1$; otherwise, $r_{f}<r_{p}$, and $D<1, q>1$. In China's case, the average city size ratios $\left(r_{\mathrm{p}}\right)$ of all four years are significantly smaller than 2 (Table 1$)$, implying the relatively strong position of the state in the Chinese context.

The influence of the state is also supported by the evidence that the rank-size patterns probably depart from Zipf's law. First, the points in the log-log plots do not align in a straight line. Second, the Zipf exponents are significantly smaller than the theoretically expected value of 1 . Third, many cities are not included in the considerably narrow scaling ranges. Thus, Zipf's law may not be the best for the rank-size distribution model of Chinese cities where the goodness of fit is concerned. However, to conclude that China's city size distribution does not follow Zipf's law would be an insufficient conclusion, because we see a clear evolving trend of China's city size distribution towards Zipf's law or rank-size rule over time. Thus, a more reasonable interpretation is that the imbalances between the state and the market in the Chinese political economy can lead to the deviation of the city size distribution from Zipf's law.

We subsequently attempt to scrutinize the state's influences on city size distributions. First, state regulations have resulted in significant underdevelopment of large cities, which has been observed previously [41-46]. Table 1 shows that the city size ratios $\left(r_{\mathrm{p}}\right)$ of the top classes in each year are all significantly smaller than 2 . In 2010, for example, we can determine that the city size ratios of the top four classes are $P_{1} / P_{2}=1.362, P_{2} / P_{3}=1.521$, and $P_{3} / P_{4}=1.515$. Accordingly, the rank-size distribution also indicates that the top cities are all below the trend line (Figure 4). The underdevelopment of large cities may be attributed principally to the urban development policy issued by the central government in the 1980s, which stated, "strictly control the size of large cities, rationally develop medium-sized cities, and actively develop small cities and towns". Although this policy became less rigid at the national level after the late 1990s, the local governments of these large cities continued to regulate their own growth. Many institutional and policy barriers, such as the Hukou status, education opportunity, and health care, prevented the population from agglomerating in these large cities. At the same time, "super-large city diseases," including environmental pollution, traffic jams, and high housing prices, continued to be critical restrictions for their growth. Theoretically, China's largest cities, such as Shanghai, Beijing, Guangzhou, and Shenzhen, have the potential to increase their respective population sizes.

Second, the state has restricted the growth of the cities at the bottom of the city hierarchy. These cities include the small cities, and also refer to those counties and towns which have potential to grow larger but are restricted by the administrative system. Consequently, these cities became too small to be included in the scaling range of the hierarchy of cities, forming the phenomena of the droopy tail and narrow scaling range. With some exceptions, few studies have focused on this problem [14]. With the country's huge urban population in 2010 (approximately 660 million), China had only approximately 550 cities within the 
scaling range. By contrast, the 1990 population census data indicated that more than 2400 cities were within the scaling range based on the city size distribution of the US [47]. Using remote sensing images of the urban built-up region to measure city size, more than 30,000 cities in the US were included in the scaling range in 2010, as well as more than 5000 cities in Germany and at least 1000 cities in both the UK and France $[29,48,49]$. The evidence from these countries presents empirical support to the claim that China lacks a sound base at the lower classes of the city hierarchy because of the underdevelopment of small cities.

The urban administrative system is one of the key instruments used by the central government to regulate the development of cities at various levels according to administrative statuses (xingzheng dengji). This system has four basic administrative levels, namely, province, prefecture, county, and township and town levels [50]. At the national level, resources, quotas, and policies are allocated downward from the central government through the political hierarchy. Cities or other units at high administrative levels are imbued with more political and economic powers than other units. At the local level, county-level cities and counties are under the administrative "control" of a city at or above the prefecture level. The system is termed as "city-governing counties", and the county is called a "municipally affiliated county" (shi guan xian). The "city-governing counties" policy has been widely implemented since the 1980s. Superior cities have been given more political powers and development opportunities, whereas subordinate counties or county-level cities are obligated to follow the interest of superior cities [51]. Therefore, the administrative level contributes substantially to differences in urban growth rates, that is, higher administrative level cities may grow more rapidly than those at the lower administrative level. This distinctive mechanism is highly different from that in market economies. In countries with market economies, investment decisions and the allocation of producer goods are seldom influenced by the political or administrative level of cities.

To sum up, state control has two principal effects on China's city size distribution. First, cities at the top of the urban hierarchy are strictly regulated in their population size and, second, cities at the bottom have also been governed administratively. Both of these effects have squashed the data points in the city size distribution log-log plot, resulting in its departure from the standard Zipf distribution.

\section{Discussion}

Theoretically, this study aims to differentiate between theory and actual status. The present situation of China's urban system can be obtained by analyzing census data. The census data are compared with the theoretical model to determine the difference between the two. As described in the previous sections, we examine the characteristics of China's city size distribution by Zipf's law and by decomposing Zipf's law into two opposing dynamic processes through an urban hierarchy with a cascade structure model. Zipf's law can reflect the macro-characteristics of city size distribution, such as goodness of fit, scaling range, and the scaling exponent. The cascade structure model is employed to reveal the dynamic processes of the urban system evolution based on the two exponential functions. The cascade structure model of cities can also reflect the tendency of urban evolution in terms of the balance between equity and efficiency and the unity of opposites between the state and the market forces. Zipf's law reflects an orderly city size distribution to balance the two opposing forces.

The empirical results of the two models are consistent. First, China's city size distribution appears to deviate from the Zipf distribution, with imperfect curve fitting compared with the log-normal distribution and three-parameter Zipf-type model [29]. Second, the narrow scaling range indicates that cities at the top and bottom of the urban hierarchy are underdeveloped because of state regulations. Third, China's urban system has not yet reached the point of balance between equity for the parts or individuals and efficiency of the entire urban system, as indicated by the fractal dimension values that are signifi- 
cantly larger than 1 . Thus, the causes of these problems are excessive state regulations in China's economy.

This study has three main limitations: first, the inconsistent criteria used to measure city size. As stated previously, "city population" (shi renkou) is the best index to measure the actual size of a Chinese city, but its shortcoming is the variation in the criteria across the years. Especially, the "city population" of the 1990 population census was clearly incomparable with the other three years. Therefore, the non-agricultural population was used as an approximation. Although such a substitution may lead to slight inconsistencies, the data used in this study are the most comparable data that we can obtain. Consequently, the actual Zipf exponent $q$ of 1990 should have been slightly higher than the estimated value (0.816), while the actual fractal dimension $D$ should be smaller than the value of 1.283. However, the differences should be very small. In general, we are confident that our analysis of the evolutionary trend of China's urban system is still valid despite the aforementioned shortcomings of the data.

Second, our analysis is based on the administrative definition of a "city proper", and we understand that the issue of city delimitation is key to urban studies in China. The administrative definition of a city is another salient factor affecting the fitting of models to the data and the estimation of the scaling exponents. Considering the US as an example, previous studies have verified that the scaling exponents vary when using different city definitions [31]. The scaling exponent is significantly different from 1 when the population of the "city proper" is used, whereas the scaling exponent is significantly closer to 1 if the population of the "urbanized area" is used. "City" in China refers mainly to an areatype administrative unit. However, a statistically defined term of "city" is clearly lacking. We exclude the subordinate counties of prefecture-level cities when enumerating the city population to reduce the effects of ambiguity. Thus, the population size of the city is relatively close to the size of the "urbanized area" in the US. Although the results are also slightly larger than the actual sizes, they are acceptable for our analysis. Further work can employ the identification of cities from a geographical perspective, such as work by Swerts [14], and compare it with the administrative definition of cities, which may lead to interesting conclusions.

Third, our current analysis only considers the urban system development during the past three decades, and further work can extend to a longer historical period and investigate differences between urban systems of different countries on a geo-historical basis.

\section{Conclusions}

Based on a theoretical framework that decomposes Zipf's law into two exponential functions through an urban hierarchy with a cascade structure model, this study examines the evolution of city size distributions of China's urban system from 1982 to 2010. Over time, China's urban system has exhibited self-organization features which are evidenced by the decline in the fractal dimension value of city size distribution over the past three decades, from 1.312 to 1.111. This evolution toward a self-organization system can be attributed mainly to the implementation of the reform and opening-up policies and the establishment of the socialist market economy. However, we found that rank-size patterns deviate slightly from the standard Zipf distribution, as indicated by the Zipf exponents being significantly smaller than the expected value of 1 , the unclear and significantly narrow scaling ranges, and the imperfectness of the curve fitting. One major cause of such deviation may be the excessive state interventions that occurred even in post-reform China.

China's city size distribution has not reached the point of equilibrium between equity for the parts or individuals and the efficiency of the entire urban system. However, China is expected to maintain a relatively rapid urbanization in the coming decades, and the urban system will continue to restructure and evolve accordingly. Theoretically, reducing state regulation will lead to a standard Zipf distribution. China has increasingly relaxed and amended numerous regulations that have controlled urban development. For example, considering the unbalanced relations between superior and subordinate cities, the central 
government has amended the "city-governing counties" system by allowing subordinate counties and county-level cities to have independent fiscal and budget systems and experimenting with the "province-governing counties" system in a number of developed coastal provinces. In addition, the Hukou system has also been amended numerous times, with the amendments including the granting of more city resident properties to rural-urban migrants. Such new reforms could lead to the evolution of China's urban system into a more natural system developed by the market and from bottom-up forces, with a city size system that will be closer to Zipf's law of self-organization.

Author Contributions: Conceptualization, J.W. and Y.C.; methodology, J.W. and Y.C.; software, J.W.; validation, J.W.; formal analysis, J.W.; investigation, J.W.; resources, J.W.; data curation, J.W.; writing—original draft preparation, J.W.; writing—review and editing, J.W. and Y.C.; visualization, J.W.; supervision, J.W.; project administration, J.W.; funding acquisition, J.W. and Y.C. All authors have read and agreed to the published version of the manuscript.

Funding: This research was funded by the National Natural Science Foundations of China (Grant No. 41701182 and 41671167). The funders had no role in the design of the study; in the collection, analyses, or interpretation of data; in the writing of the manuscript, or in the decision to publish the results.

Institutional Review Board Statement: Not applicable.

Informed Consent Statement: Not applicable.

Data Availability Statement: Data available on request due to restrictions e.g., privacy or ethical. The data presented in this study are available on request from the corresponding author. The data are not publicly available due to the data management policy of the National Bureau of Statistics of China.

Conflicts of Interest: The authors declare no conflict of interest.

\section{References}

1. Allen, P.M. Cities and Regions as Self-Organizing Systems: Models of Complexity; Gordon and Breach Science Pub: Amsterdam, The Netherlands, 1997.

2. Allen, P.M.; Sanglier, M. Urban evolution, self-organization, and decision making. Environ. Plan. A 1981, 13, 167-183. [CrossRef]

3. Portugali, J. Self-Organization and the City; Springer Science \& Business Media: Berlin, Germany, 2012.

4. Haken, H.; Portugali, J. A synergetic approach to the self-organization of cities and settlements. Environ. Plan. B Plan. Des. 1995, 22, 35-46. [CrossRef]

5. Batty, M. Hierarchy in cities and city systems. In Hierarchy in Natural and Social Sciences; Pumain, D., Ed.; Springer: Dordrecht, The Netherlands, 2006; pp. 143-168.

6. Alperovich, G. The size distribution of cities: On the empirical validity of the rank-size rule. J. Urban Econ. 1984, 16, 232-239. [CrossRef]

7. Berry, B.J.L.; Okulicz-Kozaryn, A. The city size distribution debate: Resolution for US urban regions and megalopolitan areas. Cities 2012, 29 (Suppl. 1), S17-S23. [CrossRef]

8. Carroll, G.R. National city size distributions what do we know after 67 years of research? Prog. Hum. Geogr. 1982, 6, 1-43. [CrossRef]

9. Anderson, G.; Ge, Y. The size distribution of Chinese cities. Reg. Sci. Urban Econ. 2005, 35, 756-776. [CrossRef]

10. Benguigui, L.; Blumenfeld-Lieberthal, E. Beyond the power law-a new approach to analyze city size distributions. Comput. Environ. Urban Syst. 2007, 31, 648-666. [CrossRef]

11. Benguigui, L.; Blumenfeld-Lieberthal, E. A dynamic model for city size distribution beyond Zipf's law. Phys. A Stat. Mech. Appl. 2007, 384, 613-627. [CrossRef]

12. Chen, Y.; Zhou, Y. Scaling laws and indications of self-organized criticality in urban systems. Chaos Solit. Fractals 2008, 35, 85-98. [CrossRef]

13. Gangopadhyay, K.; Basu, B. City size distributions for India and China. Phys. A Stat. Mech. Appl. 2009, 388, 2682-2688. [CrossRef]

14. Swerts, E. A Data Base on Chinese Urbanization: ChinaCities. Cybergeo: European Journal of Geography: Paris, France. 2017. Available online: http://journals.openedition.org/cybergeo/28554 (accessed on 21 September 2017). [CrossRef]

15. Swerts, E.; Liao, L. The Chinese Urban System: Political Evolution and Economic Transition. In International and Transnational Perspectives on Urban Systems.; Springer: Singapore, 2018; pp. 215-235.

16. Wu, F. Emerging cities and urban theories: A Chinese perspective. In Theories and models of urbanization; Pumain, D., Ed.; Springer: Berlin, Germany, 2019; pp. 171-182.

17. Wu, F.; Xu, J.; Yeh, A.G.O. Urban Development in Post-Reform China: State, Market, Space; Routledge: New York, NY, USA, 2007. 
18. Pannell, C.W. Recent growth and change in China's urban system. In Urban Development in Modern China; Ma Laurence, J., Hanten, E.W., Eds.; Westview Press: Boulder, CO, USA, 1982; pp. 91-114.

19. Chang, S.D. The changing system of Chinese cities. Ann. Assoc. Am. Geogr. 1976, 66, 398-415. [CrossRef]

20. Chang, S.D. Modernization and China's urban development. Ann. Assoc. Am. Geogr. 1981, 71, 202-219. [CrossRef]

21. Lin, G.C.S. Chinese Urbanism in Question: State, Society, and the Reproduction of Urban Spaces. Urban Geogr. $2007,28,7-29$. [CrossRef]

22. Fan, C.C. The vertical and horizontal expansions of China's city system. Urban Geogr. 1999, 20, 493-515. [CrossRef]

23. Zhao, S.X.B.; Zhang, L. Urban performance and the control of urban size in China. Urban Stud. 1995, 32, 813-846. [CrossRef]

24. Huang, Y. Capitalism with Chinese Characteristics: Entrepreneurship and the State; Cambridge University Press: Oxford, UK, 2008; Volume 1.

25. Yeh, A.G.O.; Yang, F.F.; Wang, J. Economic transition and urban transformation of China: The interplay of the state and the market. Urban Stud. 2015, 52, 2822-2848. [CrossRef]

26. Chan, K.W.; Buckingham, W. Is China abolishing the hukou system? China Q. 2008, 195, 582-606. [CrossRef]

27. Bak, P. How Nature Works: The Science of Self-Organized Criticality; Springer: New York, NY, USA, 1996.

28. Cristelli, M.; Batty, M.; Pietronero, L. There is More than a Power Law in Zipf. Sci. Rep. 2012, 2, 812. [CrossRef] [PubMed]

29. Chen, Y. The rank-size scaling law and entropy-maximizing principle. Phys. A Stat. Mech. Appl. 2012, 391, 767-778. [CrossRef]

30. Zipf, G.K. Human Behavior and the Principle of Least Effort; Addison-Wesley Press: Cambridge, MA, USA, 1949.

31. Gabaix, X.; Ioannides, Y.M. The Evolution of City Size Distributions. In Handbook of Regional and Urban Economics; Thisse, J.-F., Henderson, J.V., Eds.; Elsevier: London, UK, 2004; Volume 4, pp. 2341-2378.

32. Chen, Y.; Zhou, Y. The rank-size rule and fractal hierarchies of cities: Mathematical models and empirical analyses. Environ. Plan. B Plan. Des. 2003, 30, 799-818. [CrossRef]

33. Chen, Y. Modeling fractal structure of city size distributions using correlation functions. PLoS ONE 2011, 6, e24791. [CrossRef]

34. Chen, Y. The mathematical relationship between Zipf's law and the hierarchical scaling law. Phys. A: Stat. Mech. Appl. 2012, 391, 3285-3299. [CrossRef]

35. Jiang, B.; Yao, X. Geospatial Analysis and Modelling of Urban Structure and Dynamics; Springer Science \& Business Media: London, UK, 2010; Volume 99.

36. Zhou, Y.X.; Yu, H. Restructuring city population size hierarchy of China based on the Fifth Population Census (1). City Plan. Rev. 2004, 28, 49-55. (In Chinese)

37. Skinner, G.W. Regional urbanization in 19th-century China. In The City in Late Imperial China; Skinner, G.W., Ed.; Stanford University Press: Stanford, CA, USA, 1977; pp. 211-249.

38. Kornai, J. Growth, Shortage, and Efficiency: A Macrodynamic Model of the Socialist Economy; University of California Press: Berkeley/Los Angeles, CA, USA, 1982.

39. Shen, J. Understanding dual-track urbanisation in post-reform China: Conceptual framework and empirical analysis. Popul. Space Place 2006, 12, 497-516. [CrossRef]

40. Sit, V.F.S.; Yang, C. Foreign-investment-induced exo-urbanisation in the Pearl River Delta, China. Urban Stud. 1997, 34, 647-677. [CrossRef]

41. Au, C.C.; Henderson, J.V. How migration restrictions limit agglomeration and productivity in China. J. Dev. Econ. 2006, 80, 350-388. [CrossRef]

42. Ran, M.; Berry, B.J.L. Underurbanization policies assessed: China, 1949-1986. Urban Geogr. 1989, 10, 111-120. [CrossRef]

43. Song, S.; Zhang, K.H. Urbanisation and city size distribution in China. Urban Stud. 2002, 39, 2317-2327. [CrossRef]

44. Xu, X.Q.; Ouyang, N.J.; Zhou, C.S. The changing urban system of China: New developments since 1978. Urban Geogr. 1995, 16, 493-504. [CrossRef]

45. Xu, Z.; Zhu, N. City size distribution in China: Are large cities dominant? Urban Stud. 2009, 46, 2159-2185. [CrossRef]

46. Yeh, A.G.O.; Xu, X.Q. Provincial variation of urbanization and urban primacy in China. Ann. Reg. Sci. 1984, 18, 1-20. [CrossRef]

47. Chen, Y. Fractal Urban Systems: Scaling, Symmetry, and Spatial Complexity; Scientific Press: Beijing, China, 2008. (In Chinese)

48. Jiang, B.; Jia, T. Zipf's law for all the natural cities in the United States: A geospatial perspective. Int. J. Geogr. Inf. Sci. 2011, 25, 1269-1281. [CrossRef]

49. Jiang, B.; Liu, X. Scaling of geographic space from the perspective of city and field blocks and using volunteered geographic information. Int. J. Geogr. Inf. Sci. 2012, 26, 215-229. [CrossRef]

50. Ma, L.J.C. Urban administrative restructuring, changing scale relations and local economic development in China. Political Geogr. 2005, 24, 477-497. [CrossRef]

51. Zhou, Y.X.; Hu, D.P. An analysis of the impact of the city-administering-county system on the economy of the subordinate counties based on questionnaires. Econ. Geogr. 1992, 12, 8-14. (In Chinese) 